\title{
Extend of magnetic field interference in the natural convection of diamagnetic nanofluid
}

\author{
Aleksandra Roszko ${ }^{1}$ (D) Elzbieta Fornalik-Wajs ${ }^{1}$
}

Received: 31 March 2017 / Accepted: 18 September 2017 / Published online: 10 October 2017

(C) The Author(s) 2017. This article is an open access publication

\begin{abstract}
Main objective of the paper was to experimentally investigate the thermo-magnetic convection of diamagnetic fluids in the Rayleigh-Benard configuration. For better understanding of the magnetic field influence on the phenomena occurring in cubical enclosure the following parameters were studied: absence or presence of nanoparticles (single and twophase fluids), thermal conditions (temperature difference range of 5-25 K) and magnetic field strength (magnetic induction range of $0-10 \mathrm{~T}$ ). A multi-stage approach was undertaken to achieve the aim. The multi-stage approach means that the forces system, flow structure and heat transfer were considered. Without understanding the reasons (forces) and the fluid behaviour it would be impossible to analyse the exchanged heat rates through the Nusselt number distribution. The forces were determined at the starting moment, so the inertia force was not considered. The flow structure was identified due to the FFT analysis and it proved that magnetic field application changed the diamagnetic fluid behaviour, either single or two-phase. Going further, the heat transfer analysis revealed dependence of the Nusselt number on the flow structure and at the same time on the magnetic field. It can be said that imposed magnetic field changed the energy transfer within the system. In the paper, it was shown that each of presented steps were linked together and that only a comprehensive approach could lead to better understanding of magnetic field interference in the convection phenomenon.
\end{abstract}

Aleksandra Roszko roszko@agh.edu.pl

1 Department of Fundamental Research in Energy Engineering, AGH University of Science and Technology, al. Mickiewicza 30, 30-059 Krakow, Poland

\section{Introduction}

During the last years, number of possible nanofluid applications increases very fast due to the intensive investigations. The research works are going in various directions, but one of them is connected with Maxwell's idea [1], which involves addition of the particles to single-phase fluid to obtain enhanced thermal conductivity. He also proposed a formula to calculate the thermal conductivity of nanofluid in dependence on the nanoparticles amount, which is commonly used, also in presented work. The first successful nanofluid preparation and experimental study were reported by Choi [2], and since 90's this research area is still expanding. The other thermal nanofluid properties were also tested to find the difference between it and base fluid (e.g. [3-5]), however there is no clear theory on this matter [5] due to complexity of issue. Nevertheless, the nanofluids have a lot of potential in the energy sector through a heat transfer reinforcement, for example as the working media in the heat exchangers [6, 7]. Addition of the particles is considered as the passive heat transfer enhancement method, while another way to intensify the processes of heat transport is application of an active method - e.g. utilization of the magnetic field. The previous and recent works on the paramagnetic single-phase fluids [8-12] reported significant increase of transferred heat rates. These investigations raised an attention placed on the nanofluids as possible to utilize media in this area. Authors' first investigations of low concentration nanofluids in the strong magnetic environment were encouraging [13-16].

In the paper an experimental study of diamagnetic fluids convection in the magnetic field are presented. The single (base fluid) and two-phase fluids (silver/water nanofluid) were considered within the conducted investigations. The nature and extend of magnetic field interference in the natural convection phenomenon were key 
Table 1 Properties of the analysed substances

\begin{tabular}{|c|c|c|c|c|c|c|c|}
\hline Property & Symbol & Unit & Water at $\Delta T=5 \mathrm{~K}$ & $\operatorname{Ag} 0.1$ at $\Delta T=5 \mathrm{~K}$ & $\mathrm{Ag} 0.1$ at $\Delta T=15 \mathrm{~K}$ & $\operatorname{Ag} 0.1$ at $\Delta T=25 \mathrm{~K}$ & $\mathrm{Ag}$ \\
\hline Thermal conductivity & $k_{\mathrm{nf}}$ & $\mathrm{W} \cdot(\mathrm{mK})^{-1}$ & 0.5998 & 0.6018 & 0.6106 & 0.6191 & 429 \\
\hline Density & $\rho_{\mathrm{nf}}$ & $\mathrm{kg} \cdot \mathrm{m}^{-3}$ & 997.96 & 1009.70 & 1008.54 & 1007.10 & 10,500 \\
\hline Specific heat & $c_{\mathrm{p}, \mathrm{nf}}$ & $\mathrm{J} \cdot(\mathrm{kg} \cdot \mathrm{K})^{-1}$ & 4181.16 & 4176.35 & 4173.67 & 4172.46 & 235 \\
\hline Thermal expansion coefficient & $\beta_{\mathrm{nf}}$ & $\mathrm{K}^{-1}$ & $21.37 \cdot 10^{-5}$ & $21.24 \cdot 10^{-5}$ & $26.27 \cdot 10^{-5}$ & $31.04 \cdot 10^{-5}$ & - \\
\hline Dynamic viscosity & $\mu_{\mathrm{nf}}$ & $\mathrm{kg} \cdot(\mathrm{m} \cdot \mathrm{s})^{-1}$ & $9.84 \cdot 10^{-4}$ & $9.84 \cdot 10^{-4}$ & $8.69 \cdot 10^{-4}$ & $7.74 \cdot 10^{-4}$ & - \\
\hline Mass magnetic susceptibility & $\chi_{\mathrm{m}}$ & $\mathrm{m}^{3} \cdot \mathrm{kg}^{-1}$ & $-8.86 \cdot 10^{-9}$ & $-8.81 \cdot 10^{-9}$ & $-8.82 \cdot 10^{-9}$ & $-8.83 \cdot 10^{-9}$ & $-2.27 \cdot 10^{-9}$ \\
\hline $\begin{array}{l}\text { Volume magnetic } \\
\text { susceptibility }\end{array}$ & $\chi$ & - & $-8.84 \cdot 10^{-6}$ & $-8.89 \cdot 10^{-6}$ & $-8.89 \cdot 10^{-6}$ & $-8.89 \cdot 10^{-6}$ & $-2.38 \cdot 10^{-5}$ \\
\hline
\end{tabular}

points in the undertaken studies. Such analysis is important since most of available data comes from the numerical models. Moreover, most of the papers considering numerical approaches treated the nanofluid as homogeneous fluid of slightly changed properties [17-19]. The experiences gained from the preliminary experiments negated such generalization, since some of the results could be explained only when the nanofluid was treated as two-phase fluid. Presented work combines the force system analysis at the beginning of process, the fluid structure and the heat transfer analysis.

\section{Experimental analysis}

The experimental investigations concern the thermo-magnetic convection phenomena of diamagnetic fluids in the RayleighBenard configuration for various thermal conditions and various values of the magnetic induction.

\subsection{Investigated fluids}

Following fluids were taken into consideration: one phase fluid (distilled water) and nanofluid (with distilled water as the base fluid and addition of the nanosized particles). In presented studies the spherical silver particles of $50-60 \mathrm{~nm}$ diameter were used. Therefore, the initial and essential stage of the experimental analysis was the accomplished with two-step proper nanofluid preparation method, which generally consisted of weighting of the required components quantities, combining them and homogenizing the mixture. The process of homogenization was done with utilization of Hielscher Ultrasonics (UP200Ht) unit for about $1 \mathrm{~h}$ with pulse mode. In accordance with [20] a cooling environment was applied, which meant that sample was placed in a container with a cold water. Ready to use nanofluid contained 0.1 volume percentage of silver nanoparticles, therefore the abbreviation $\operatorname{Ag} 0.1$ was used in this paper.

The thermo-physical properties like: density, thermal expansion coefficient, viscosity, specific heat and thermal conductivity were necessary for determination of important parameters. For further steps of analysis, due to involvement of magnetic field, the magnetic properties of working fluids had to be also taken into account. The water and silver properties values came from literature [21], while for the nanofluid they were calculated on the basis of formulas shown e.g. in [14], except for the magnetic susceptibility values, which were measured with Magnetic Susceptibility Balance (Sherwood
Fig. 1 Schematic view of the experimental facility

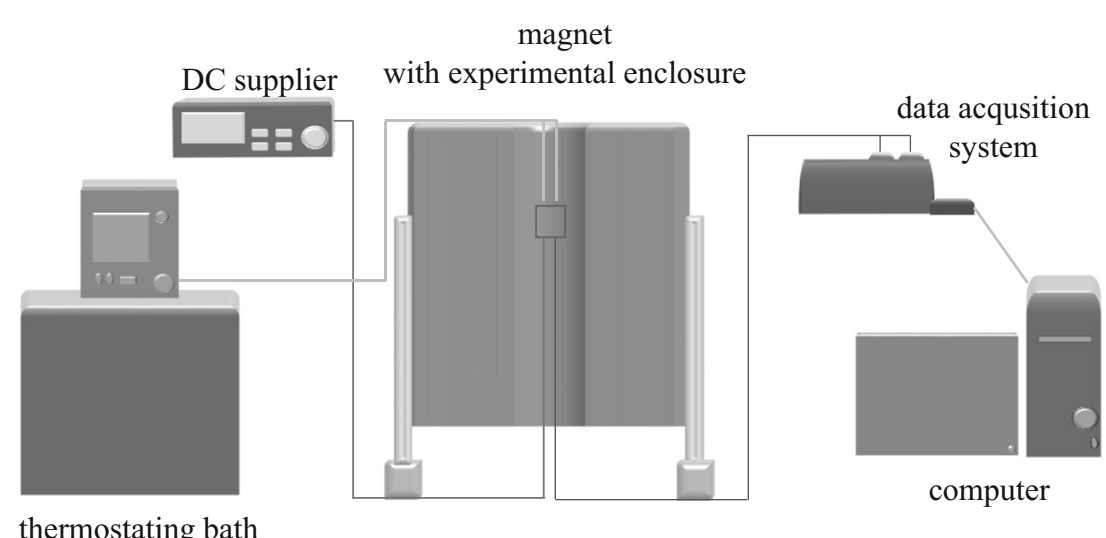

thermostating bath 


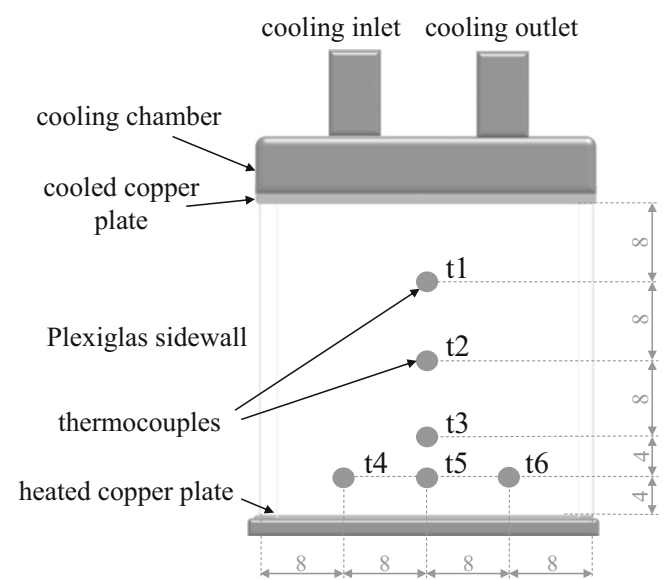

Fig. 2 Positions of six K-type thermocouples placed inside the cube, distance measured in $\mathrm{mm}$

Scientific). The working fluids' properties are summarized in Table 1. The properties of $\mathrm{Ag} 0.1$ at various temperature values were used only for the heat transfer analysis.

\subsection{Experimental facility}

Diamagnetics are the substances, which in the normal conditions are treated as non-magnetic. The thermo-magnetic convection analysis of such substances (either single or twophase) required strong magnetic field application. In this research, the superconducting magnet (Sumitomo Heavy Industries) provided various values of the magnetic induction square gradient (up to $900 \mathrm{~T}^{2} / \mathrm{m}$ ) into the system. The experimental cubical enclosure filled with tested fluid was placed in the magnet working section. The cube was of $0.032 \mathrm{~m}$ size, its sidewalls were made of Plexiglas and the horizontal ones were made of copper. The cooling chamber was located above upper wall, while the heater made of a nichrome wire was under bottom plate, therefore the analysed phenomenon was convection at the Rayleigh-Benard configuration (heated from the bottom and cooled from the top). The thermostating bath was delivering the water of constant temperature (of about $291 \mathrm{~K})$ to the cooling chamber. The heater was connected to the DC supply unit. The required temperature difference was obtained through adjustment of the power supply resulting in particular temperature of heated wall. Schematic view of the experimental facility is presented in Fig. 1.

\subsection{Temperature measurements}

Since one of analysed problems was referring to the heat transfer phenomenon, the most important measurements were related to the temperature. Therefore, three T-type thermocouples (of $0.5 \mathrm{~mm}$ diameter) were located in each of the copper horizontal plates to get the temperature difference. Moreover, six K-type thermocouples (of $0.1 \mathrm{~mm}$ diameter) were additionally placed inside the cube, at the distance of $5 \mathrm{~mm}$ from the wall. Position of these six thermocouples is marked in Fig. 2. All thermocouples were calibrated in accordance with recommendation of the acquisition system producer (National Instruments), and the accuracy of $\pm 0.1 \mathrm{~K}$ was obtained.

The signals from all temperature sensors were acquired during entire experiments and recorded on a computer. They constructed the data base for further steps of the analysis.

\subsection{Position in the magnetic field}

The experimental enclosure was placed in the magnet working section, at the location associated with occurrence of the magnetic induction square gradient $\left(\operatorname{grad} \mathbf{B}^{2}\right)$ maximal value. In this position the greatest influence of magnetic force on the studied phenomenon was expected. The cube top wall was aligned with the location of maximal gradient value. This arrangement caused stronger influence of the magnetic force on the fluid in the vicinity of top (cold) wall of about $30 \%$ than near the bottom (hot) wall for both the base fluid and the particles, at each of the studied temperature differences. Thus, the magnetic force value was not symmetrical at the horizontal walls due to the selected enclosure position, schematically showed in Fig. 3.

\section{Signal analysis}

The signal from all thermocouples placed in the system was recorded and enabled the analysis of studied phenomena. Although the data were recorded for entire time, the last
Fig. 3 Schematic view of the cube location in the magnet working section and distribution of the magnetic induction square gradient

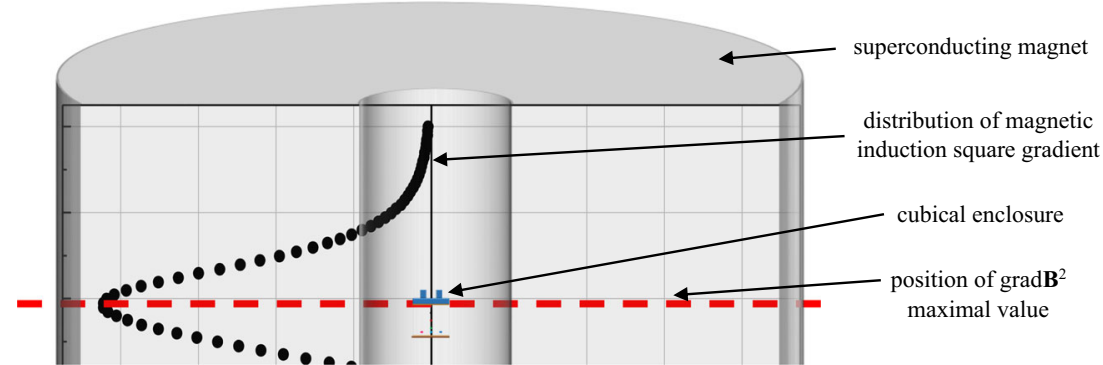



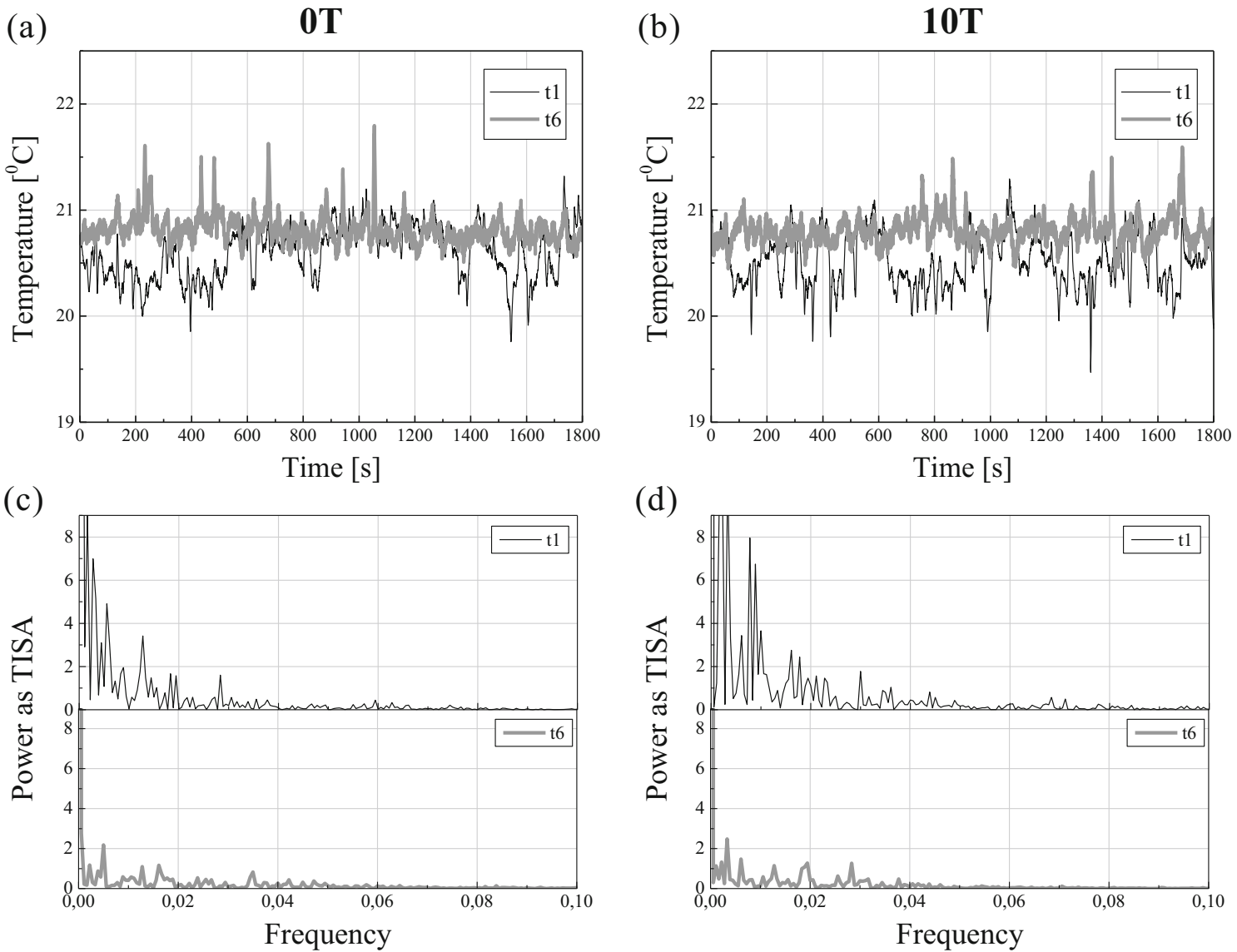

Fig. 4 The real recorded thermocouples' signals (a) for the natural convection, (b) at $10 \mathrm{~T}$ of magnetic induction and the power spectrum (c) for the natural convection, (d) at $10 \mathrm{~T}$ of magnetic induction for water at $\Delta T=5 \mathrm{~K}\left(\operatorname{Ra}_{\mathrm{T}}=2.5 \cdot 10^{6}\right)$

30 min of each measurement (steady state before changing the magnetic field strength) were taken for calculation of the forces, to get an information about the flow structure and to evaluate the heat transfer. The forces system analysis was performed to explore which forces were acting on the studied fluids, their direction and values. This data gave an insight about what happened within the experimental enclosure,

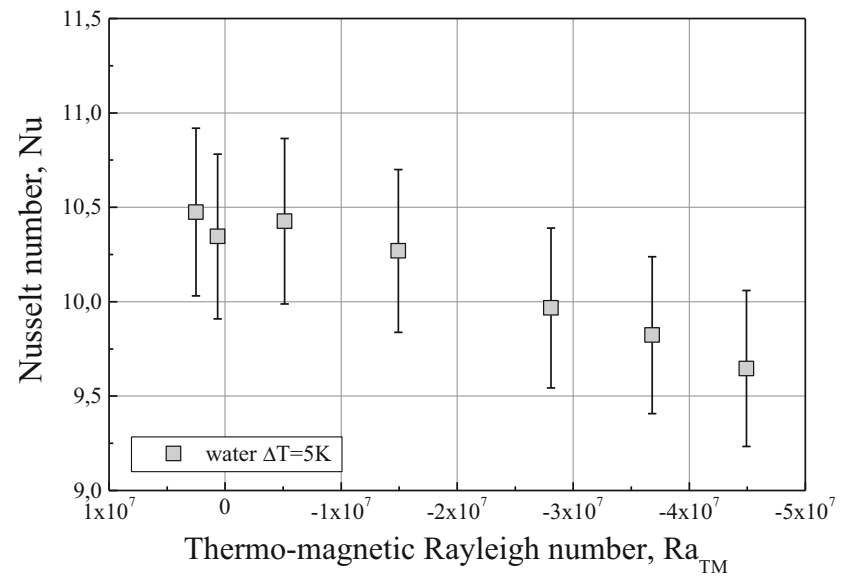

Fig. 5 The Nusselt number versus the thermo-magnetic Rayleigh number for water at $\Delta T=5 \mathrm{~K}\left(\mathrm{Ra}_{\mathrm{T}}=2.5 \cdot 10^{6}\right)$ which force was dominated and which one defined the fluid motion. The other way of getting more precise information about the flow structure and the fluid behaviour was utilization of Fast Fourier Transform analysis. The last conducted analysis was connected with global (in the system scale) effect of magnetic field on the heat transfer. The details of such approach are described in the next subsections.

\subsection{Forces}

The analysis has been started with understanding of the forces system acting on the fluid in the vicinity of horizontal walls. It should be emphasized that it was not possible to get an information about the velocity field, due to the nanofluid opaqueness. Because of those missing data only the magnetic and gravitational forces acting on the fluid were considered representing the state just at the beginning of the process. Relation between the forces values and their directions help to understand the heat transfer processes occurring in the enclosure.

Consideration of the forces in the hypothetical static state was based on two forces - gravitational and magnetic. Moreover, these forces were calculated separately for the base 
Fig. 6 Schematic view of the acting forces for water at $\Delta T=5 \mathrm{~K}\left(\mathrm{Ra}_{\mathrm{T}}=2.5 \cdot 10^{6}\right)$

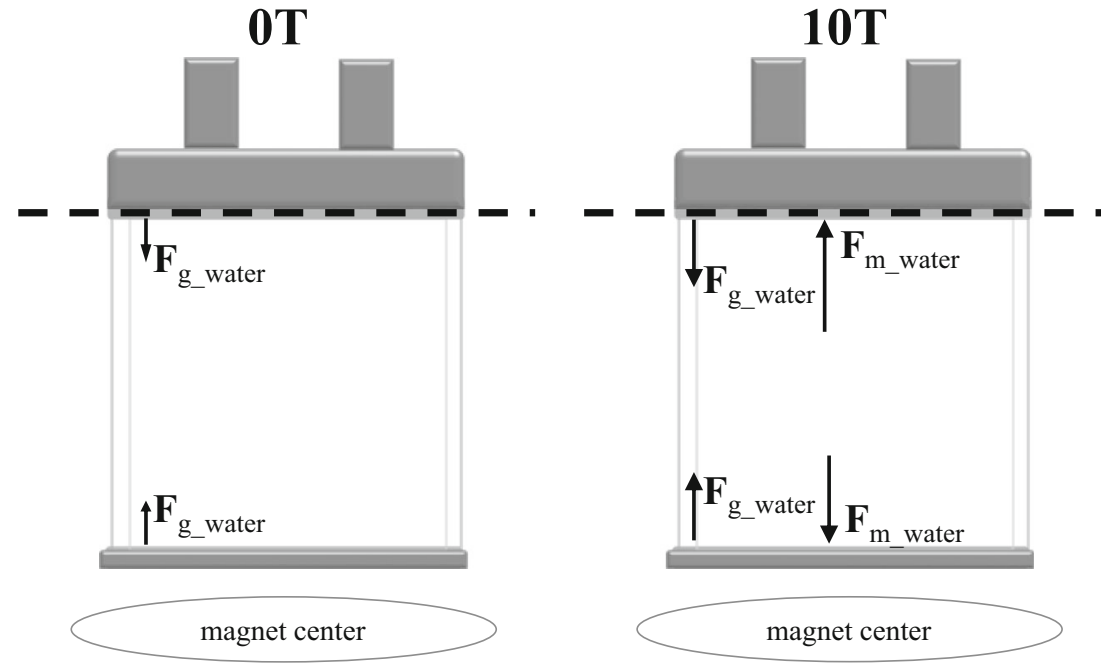

fluid and the particles. The calculations were also done for the nanofluid as homogeneous fluid, but they gave the same results as for water, that is why they are not presented here. Coming back to the forces, their mutual relation influenced the phenomenon occurring in the cube. A temperature difference caused appearance of the gravitational buoyancy force acting on the fluid. It is defined as:

$\mathbf{F}_{\mathrm{g}, f l u i d}=\rho_{\mathrm{f}, 0} \cdot \beta_{\mathrm{f}, 0}\left(T-T_{0}\right) g \cdot v_{\mathrm{f}}$

where: $\mathbf{F}_{\mathrm{g}, \text { fluid }}$ means the gravitational buoyancy force acting on specific working fluid volume $[\mathrm{N}] ; v_{\mathrm{f}}-$ is volume of the working fluid, placed in the enclosure, $\mathrm{m}^{3},\left(v_{\mathrm{f}}=0.032^{3} \mathrm{~m}^{3}=\right.$ $\left.3.28 \cdot 10^{-5} \mathrm{~m}^{3}\right) ; g-$ is the gravitational acceleration, $\mathrm{m} \cdot \mathrm{s}^{-2} ; \rho$ - is the density, $\mathrm{kg} \cdot \mathrm{m}^{-3} ; \beta$ - is the thermal expansion coefficient, $\mathrm{K}^{-1} ; T-$ is the temperature, $\mathrm{K} ; T_{0}-$ is the reference temperature, which in this case was average value of hot and cold walls' temperature, $\mathrm{K}$.

The total force acting on the particles came from direct operation of gravity on the particles but also from an influence of the fluid. It can be described as:
$\mathbf{F}_{\mathrm{g}, \text { particles }}=\left[\rho_{\mathrm{f}, 0} \cdot \beta_{\mathrm{f}, 0}\left(T-T_{0}\right)-\rho_{\mathrm{p}}\right] g \cdot f \cdot v_{\mathrm{f}}$

$\mathbf{F}_{\mathrm{g} \text {,particles }}$ - is the resultant force acting on nanoparticles (formula included gravity and buoyant forces), $\mathrm{N} ; f-$ is the volume fraction of the nanoparticles defined as: $f=\left(m_{\mathrm{p}} / \rho_{\mathrm{p}}\right) /$ $\left[\left(m_{\mathrm{p}} / \rho_{\mathrm{p}}\right)+\left(m_{\mathrm{bt}} / \rho_{\mathrm{bf}}\right)\right]$ (for nanofluid $\left.\operatorname{Ag} 0.1 f=0.001234\right),-$; Subscripts: "0" refers to the initial state which means nonconvection case and "f" and " $p$ " indicate property of the fluid and the particles, respectively.

The second group of forces was related to existence of the magnetic field and its interaction with magnetic properties of the base fluid and the nanoparticles. In accordance with [22] the forces can be formulated as follows:

$$
\begin{aligned}
& \mathbf{F}_{\mathrm{m}, \text { fluid }}=-\frac{\chi_{\mathrm{m}, \mathrm{f}} \cdot \rho_{\mathrm{f}, 0} \cdot \beta_{\mathrm{f}, 0}\left(T-T_{0}\right)}{2 \mu_{\mathrm{m}}} \nabla \mathbf{B}^{2} \cdot v_{\mathrm{f}} \\
& \mathbf{F}_{\mathrm{m}, \text { particles }}=\frac{\chi_{\mathrm{m}, \mathrm{p}} \cdot \rho_{\mathrm{p}}-\chi_{\mathrm{m}, \mathrm{f}} \cdot \rho_{\mathrm{f}, 0} \cdot \beta_{\mathrm{f}, 0}\left(T-T_{0}\right)}{2 \mu_{\mathrm{m}}} \nabla \mathbf{B}^{2} \cdot f \cdot v_{\mathrm{f}}
\end{aligned}
$$

(a)

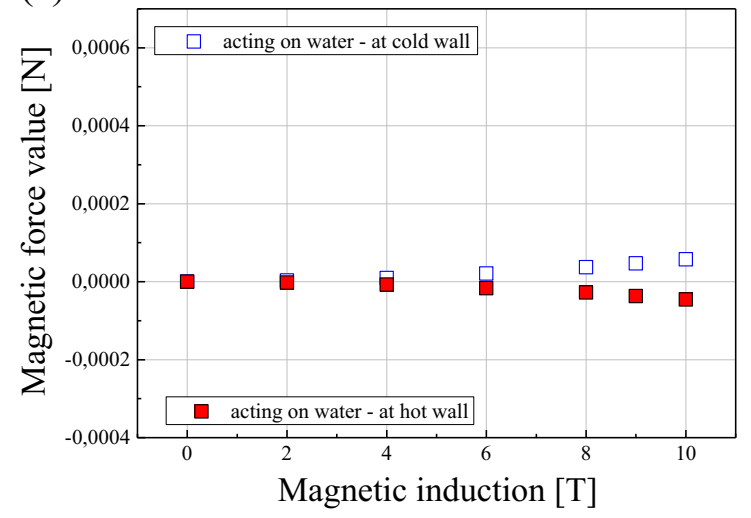

(b)

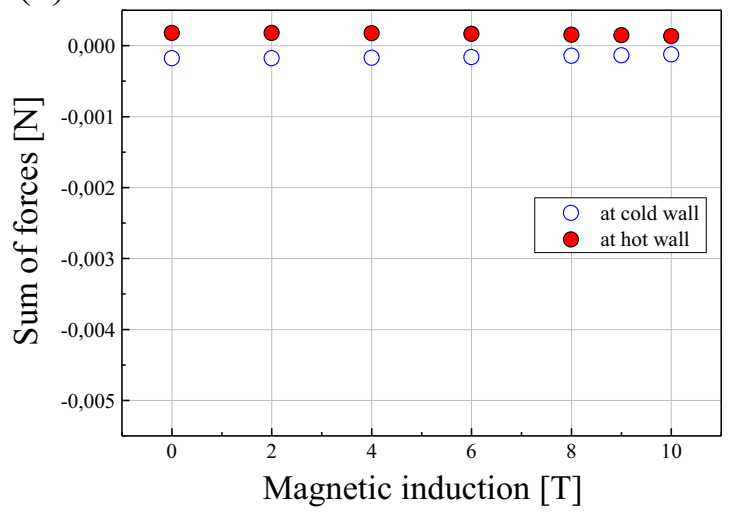

Fig. 7 The magnetic force and the sum of all forces acting in the vicinity of cold and hot walls for water at $\Delta T=5 \mathrm{~K}\left(\operatorname{Ra}_{\mathrm{T}}=2.5 \cdot 10^{6}\right)$ 

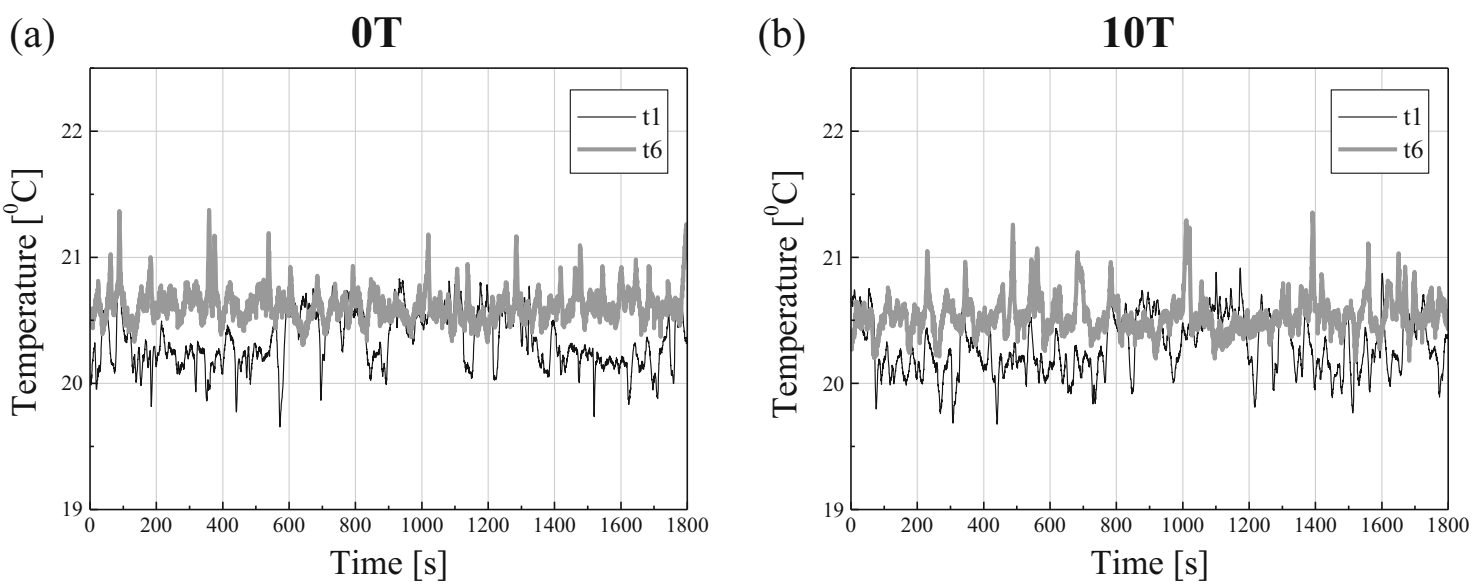

(c)

(d)
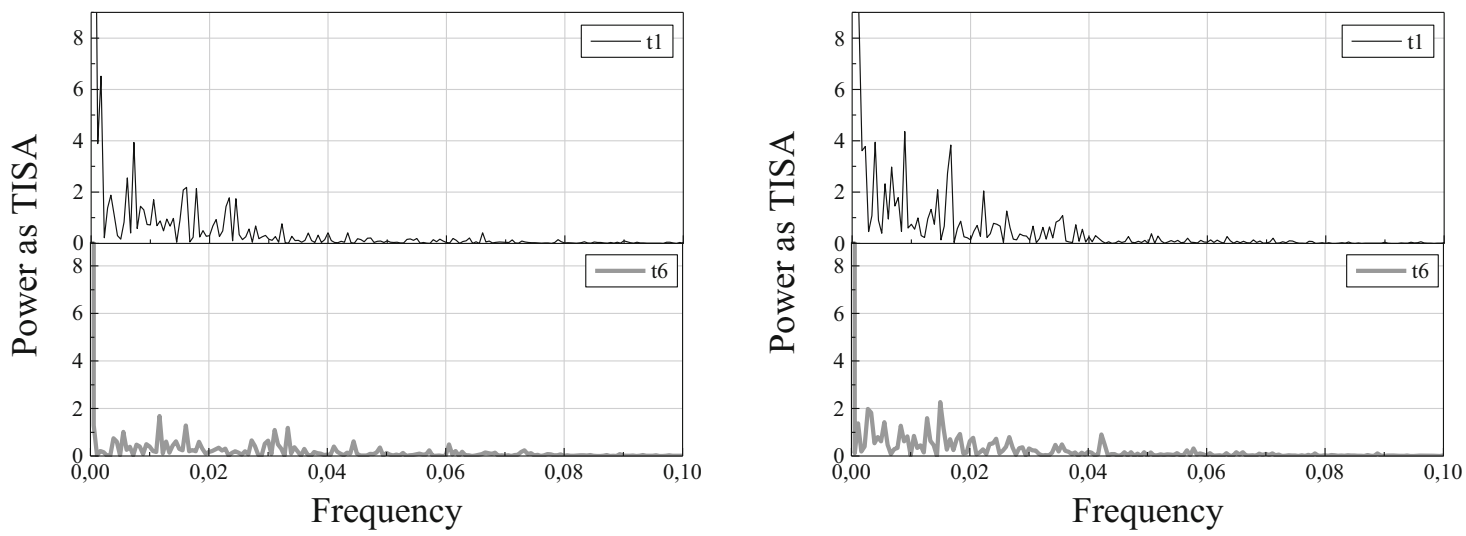

Fig. 8 The real recorded thermocouples' signals (a) for the natural convection, (b) at $10 \mathrm{~T}$ of magnetic induction and the power spectrum (c) for the natural convection, (d) at $10 \mathrm{~T}$ of magnetic induction for $\mathrm{Ag} 0.1$ at $\Delta T=5 \mathrm{~K}\left(\operatorname{Ra}_{\mathrm{T}}=2.5 \cdot 10^{6}\right)$

where: $\mathbf{F}_{\mathrm{m}}$ - is the magnetic buoyancy force acting on fluid volume (index "fluid") or particles volume (index "particles"), $\mathrm{N} ; \chi_{\mathrm{m}}-$ is the mass magnetic susceptibility, $\mathrm{m}^{3} \cdot \mathrm{kg}^{-1} ; \mu_{\mathrm{m}}-$ is the vacuum magnetic permeability, $4 \pi \cdot 10^{-7}, \mathrm{H} \cdot \mathrm{m}^{-1}=\mathrm{N} \cdot \mathrm{A}^{-2}$; $\nabla \mathbf{B}^{2}$ - is the gradient of magnetic induction square, $\mathrm{T}^{2} \cdot \mathrm{m}^{-1}$.

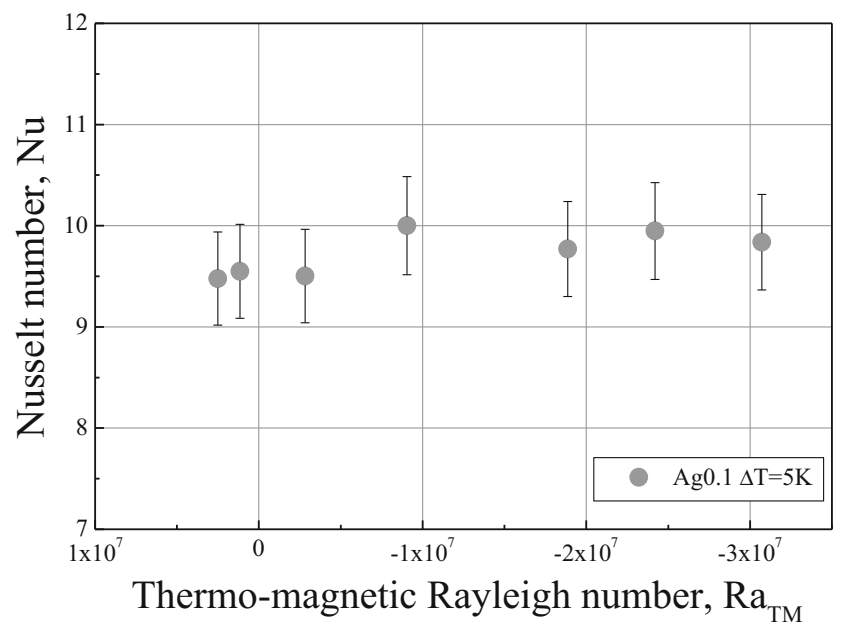

Fig. 9 The Nusselt number versus the thermo-magnetic Rayleigh number for $\mathrm{Ag} 0.1$ at $\Delta T=5 \mathrm{~K}\left(\mathrm{Ra}_{\mathrm{T}}=2.5 \cdot 10^{6}\right)$
The magnetic force definition, dedicated to the particles, included its interaction with the base fluid due to the magnetic field appearance and difference in the magnetic properties. The results and their analysis are presented in Section 4.

\subsection{Flow structure analysis}

The flow structure analysis of nanofluids is very difficult, especially due to the fact that they are non-transparent, therefore, any optical methods cannot be applied. However, the flow structure occurring in the enclosure is necessary to understand the transport phenomena. A method which seemed to be the most helpful is connected with spectral analysis of a scalar field and it comes from analysis of a turbulent transport. In this studies it was used to identify appearance of the vortical structures and their changes caused by the magnetic field. The spectral analysis was done with utilization of the FFT and the time-integral squared amplitude (TISA) method. Input data for this analysis was the thermocouples signals taken inside the cube and coming from the last 30 min before implementing the magnetic field or changing the magnetic induction value. The results are presented and discussed in Section 4. 
Fig. 10 Schematic view of the acting forces for nanofluid $\mathrm{Ag} 0.1$

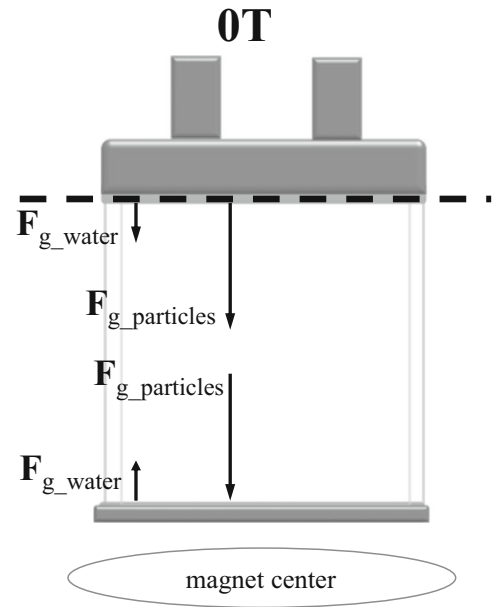

\subsection{Heat transfer analysis}

Analysis of the heat transfer consisted of two main parts, which could be characterized as the conduction state with determination of the system heat losses and the convection state. Both parts were necessary to calculate the Nusselt number as a measure of the heat transfer caused by the convection. The Nusselt number could be defined as:

$\mathrm{Nu}=Q_{\text {net_conv }} \cdot\left(Q_{\text {net_cond }}\right)^{-1}$

where: $Q_{\text {net_conv }}$ indicates the convection heat rate and $Q_{\text {net_cond }}$ - the conduction one.

The heat rates were calculated in accordance with the method presented in [23] and adopted in a following way:

$Q_{\text {net_conv }}=Q_{\text {sup }}-Q_{\text {loss }}$

$Q_{\text {theor_cond }}=\left(k \Delta T d^{2}\right) / d=k \Delta T d$

where $Q_{\text {sup }}$ represents the heat rate supplied to the system, W; $Q_{\text {loss }}$ is the lossed heat rate, $\mathrm{W} ; k$ is the thermal conductivity coefficient, $\mathrm{W} \cdot(\mathrm{mK})^{-1} ; d$ is a dimension of the cube, $\mathrm{m}$.

An assumption that the heat losses did not depend on the phenomenon occurring inside the experimental cavity made the substitution of (6) and (7) to (5) possible and lead to a following definition of the Nusselt number:

$\mathrm{Nu}=\left(Q_{\text {sup }}-Q_{\text {loss }}\right) \cdot(k \Delta T d)^{-1}$.

Calculations of the Nusselt number were conducted for studied magnetic induction values and tested temperature differences. The results are represented by the Nusselt number dependence on the thermo-magnetic Rayleigh number and described in Section 4.

Determination of the thermo-magnetic Rayleigh number was made with a following formula:

$\operatorname{Ra}_{\mathrm{TM}}=\operatorname{Ra}_{\mathrm{T}}\left[1-\gamma B_{z}\left(B_{\max }\right)^{-1}\left(\partial B_{z} / \partial z\right)\left(B_{\max }\right)^{-1}\right]$

where $\mathrm{Ra}_{\mathrm{T}}$ refers to the thermal Rayleigh number, -; which is defined as:

$\mathrm{Ra}_{\mathrm{T}}=g \beta \rho^{2} c_{\mathrm{p}}(\mu k)^{-1} d^{3} \Delta T$ (a)

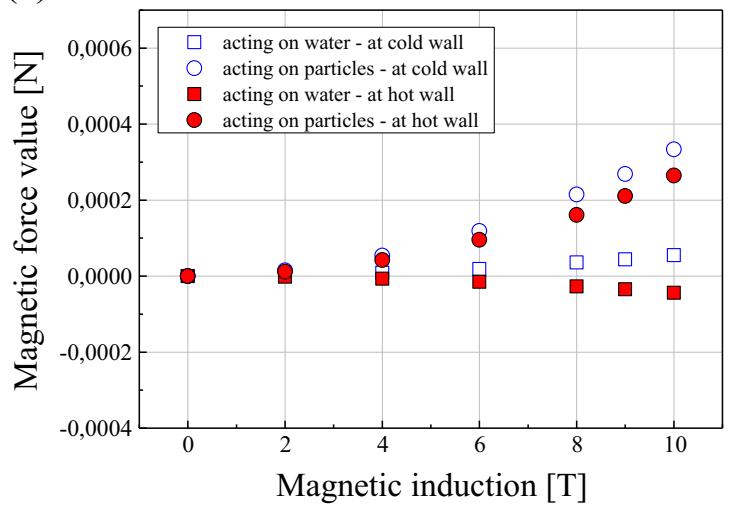

(b)

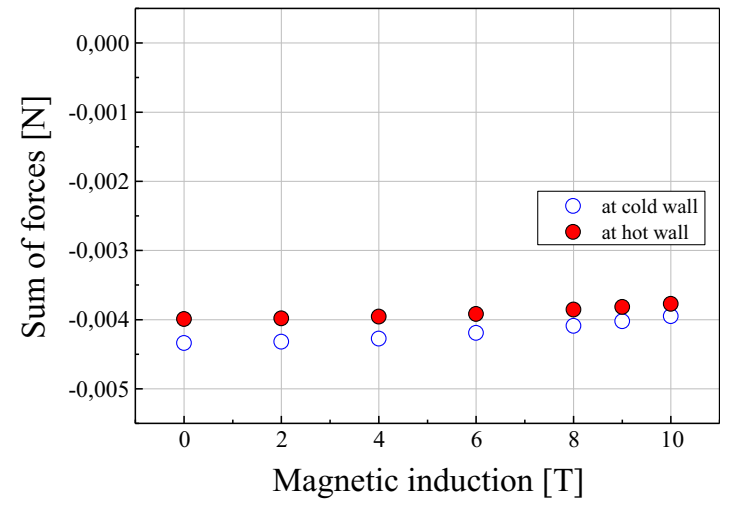

Fig. 11 The magnetic force and the sum of all forces acting in the vicinity of cold and hot walls for Ag0.1 at $\Delta T=5 \mathrm{~K}\left(\operatorname{Ra}_{\mathrm{T}}=2.5 \cdot 10^{6}\right)$ 

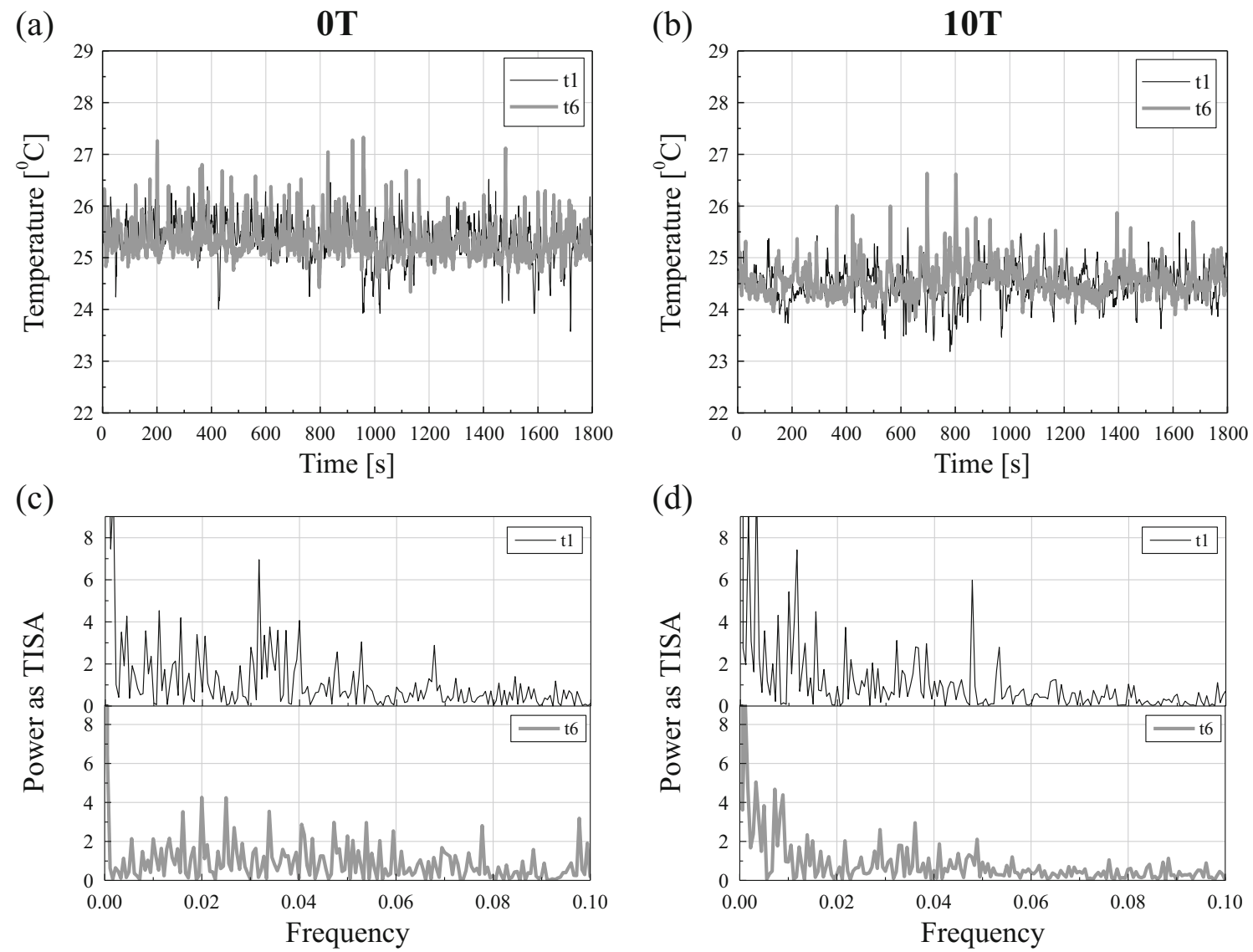

Fig. 12 The real recorded thermocouples' signals (a) for the natural convection, (b) at $10 \mathrm{~T}$ of magnetic induction and the power spectrum (c) for the natural convection, $(\mathbf{d})$ at $10 \mathrm{~T}$ of magnetic induction for $\mathrm{Ag} 0.1$ at $\Delta T=15 \mathrm{~K}\left(\operatorname{Ra}_{\mathrm{T}}=10^{7}\right)$

while $\gamma$ is the magnetization number, - ; described as:

$\gamma=\chi_{\mathrm{m}} B_{\max }^{2}\left(\mu_{\mathrm{m}} g d\right)^{-1}$

and $c_{\mathrm{p}}$ is the specific heat, $\mathrm{J} \cdot(\mathrm{kg} \cdot \mathrm{K})^{-1} ; \mu$ is the dynamic viscosity, $\mathrm{kg} \cdot(\mathrm{m} \cdot \mathrm{s})^{-1} ; k$ is the thermal conductivity, $\mathrm{W} \cdot(\mathrm{mK})^{-1} ; d$

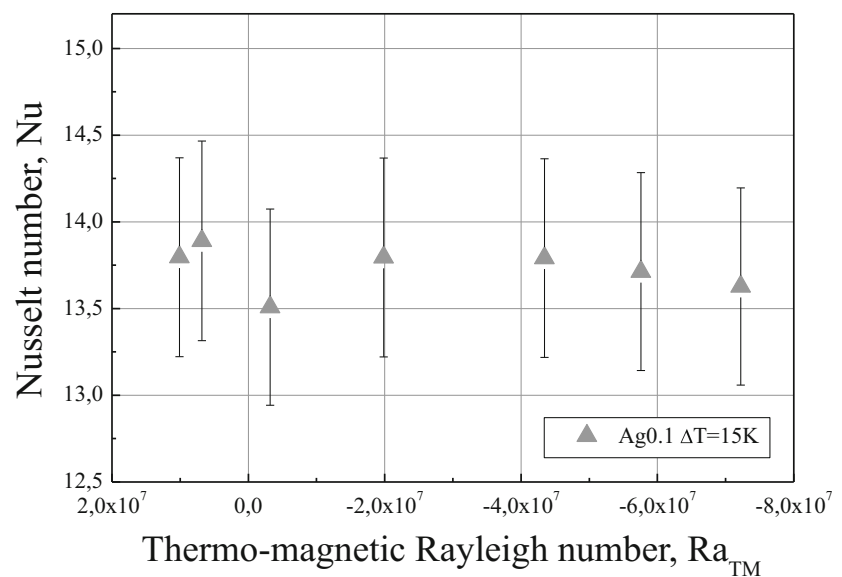

Fig. 13 The Nusselt number versus the thermo-magnetic Rayleigh number for $\mathrm{Ag} 0.1$ at $\Delta T=15 \mathrm{~K}\left(\mathrm{Ra}_{\mathrm{T}}=10^{7}\right)$ is the characteristic dimension, $\mathrm{m} ; \Delta T$ is the temperature difference, $\mathrm{K} ; B_{\mathrm{z}}$ is the magnetic induction at the top wall of cubical enclosure. The value of $B_{z}$ and $\operatorname{grad} B_{z}$ were numerically calculated [13] according to the superconducting magnet coil technical data which includes detailed information about the geometry and the electrical current flowing through the system [24] and led to the relations:

$B_{z}=0.6265 \cdot B_{\max }$

$\partial B_{z} / \partial z=-5.8742 \cdot B_{\max }$.

\section{Results and discussion}

Before going directly to the results and their analysis Authors would like to describe the sequence of figures in the particular cases. As the first figure is the measured temperature signal together with the FFT spectral analysis. In this paper the thermocouples $t 1$ and t6 were taken into account as the most representative for vicinity of the cooled and heated walls, respectively. Thermocouple t6 was selected as the one, which demonstrated the clearest 
(a)

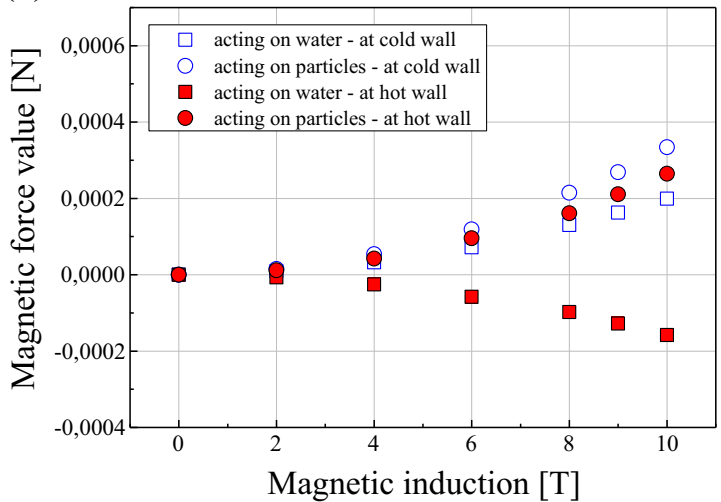

(b)

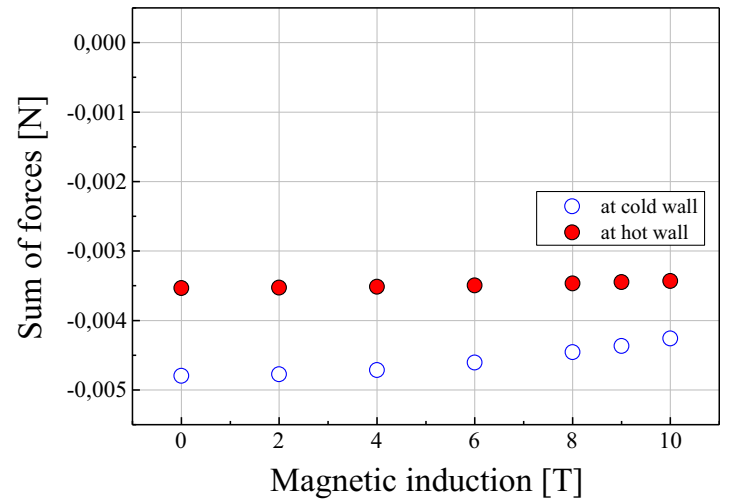

Fig. 14 The magnetic force and the sum of all forces acting in the vicinity of cold and hot walls for $\operatorname{Ag} 0.1$ at $\Delta T=15 \mathrm{~K}\left(\operatorname{Ra}_{\mathrm{T}}=10^{7}\right)$

response to temperature changes among all thermocouples placed near the hot wall. The next figure is the Nusselt number distribution, which provides information about global heat transfer phenomenon influenced by the magnetic field presence. A schematic view of the forces is shown as the third successive figure, which visualizes direction of the acting forces in the vicinity of the walls.
This figure appeared only once for water and nanofluid since mutual orientation of the forces did not change for various thermal conditions. The only change in the system was related to an increase of forces magnitudes with increasing temperature difference. The magnetic force and the sum of all forces in the vicinity of hot and cold walls are demonstrated in the last figure, from the series. The (a)

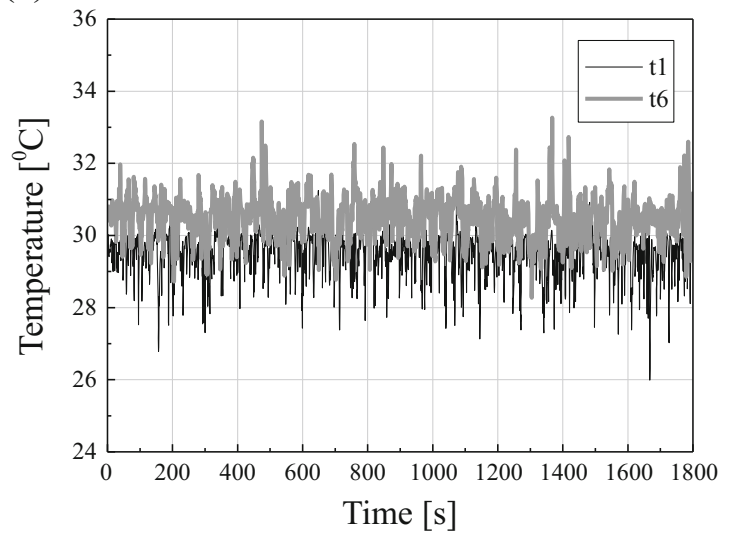

(c)

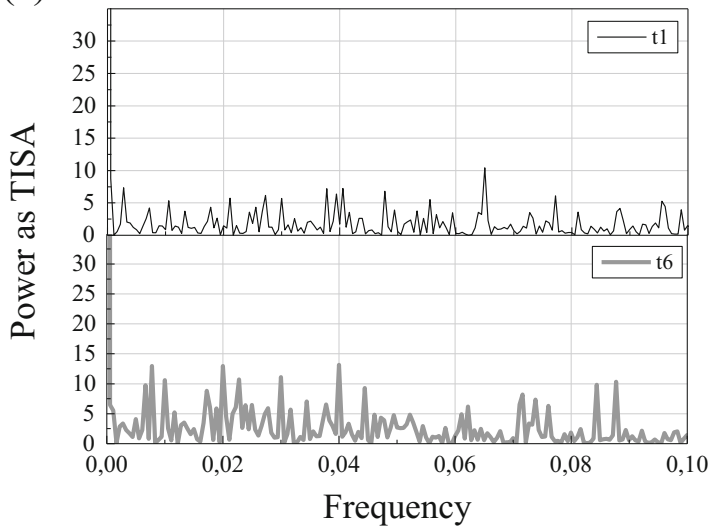

(b) $10 \mathrm{~T}$

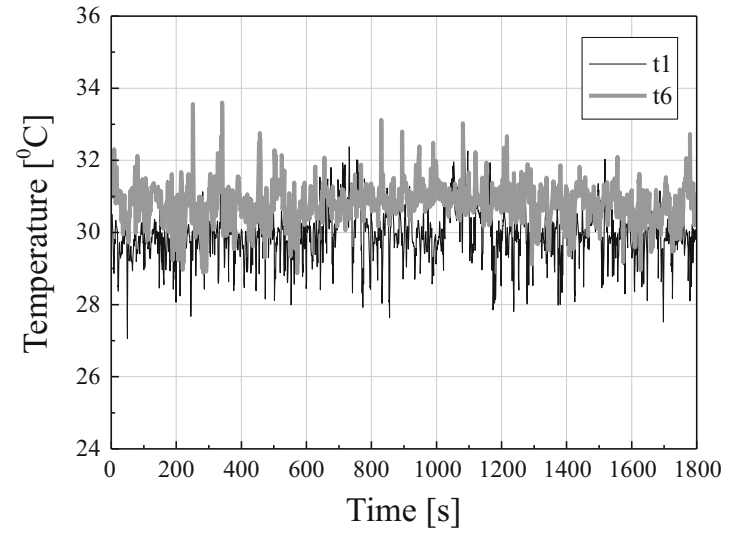

(d)

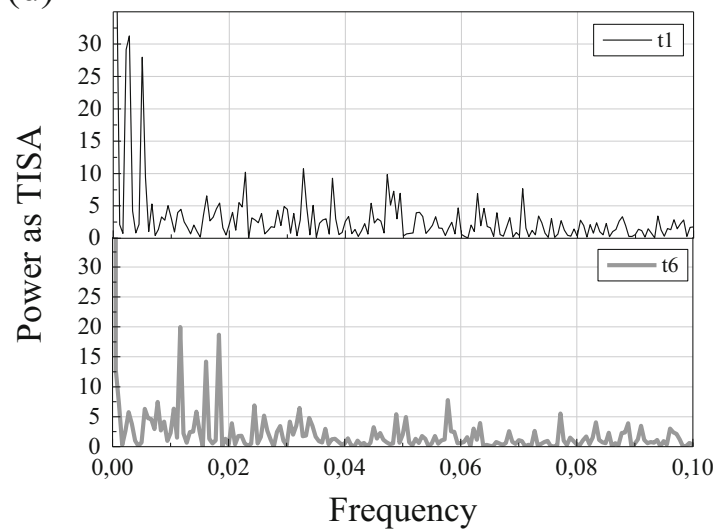

Fig. 15 The real recorded thermocouples' signals (a) for the natural convection, (b) at $10 \mathrm{~T}$ of magnetic induction and the power spectrum (c) for the natural convection, (d) at $10 \mathrm{~T}$ of magnetic induction for $\mathrm{Ag} 0.1$ at $\Delta T=25 \mathrm{~K}\left(\mathrm{Ra}_{\mathrm{T}}=2.2 \cdot 10^{7}\right)$ 


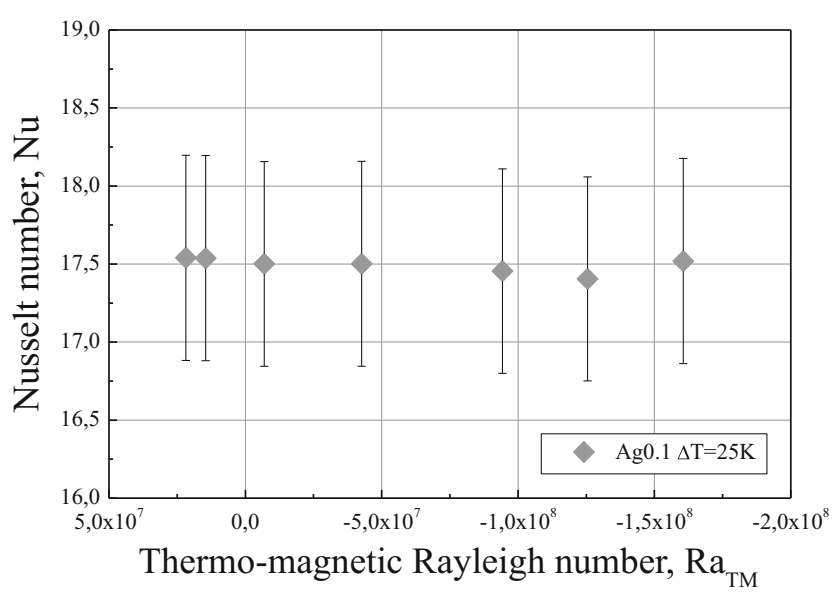

Fig. 16 The Nusselt number versus the thermo-magnetic Rayleigh number for $\mathrm{Ag} 0.1$ at $\Delta T=25 \mathrm{~K}\left(\mathrm{Ra}_{\mathrm{T}}=2.2 \cdot 10^{7}\right)$

sum of forces should be understand as a sum of every force at the vicinity of each wall, e.g. for water the gravitational and magnetic forces were added together, and for $\mathrm{Ag} 0.1$ the sum have also included the forces acting on the base fluid as well as acting on the particles. The solid symbols represent the forces close to the heated wall, while the empty ones - close to the cooled wall.

Analysis of water was done for temperature difference of $5 \mathrm{~K}\left(\mathrm{Ra}_{\mathrm{T}}=2.5 \cdot 10^{6}\right)$ and magnetic induction values in the range of $0-10 \mathrm{~T}$. However, the thermocouples signal and the energy spectrum are presented only at 0 and $10 \mathrm{~T}$ of magnetic induction in Fig. 4. The results indicated in Fig. $4 \mathrm{a}, \mathrm{b}$ corresponded with the real acquired signals and Fig. $4 \mathrm{c}$, $\mathrm{d}$ with the FFT and spectral analysis results. In the upper part of enclosure the vortical structure seemed to be more developed than in the lower part (Fig. 4c), which caused the convection characterised by the Nusselt number about 10.5 (Fig. 5). After application of the magnetic field to the system, the magnetic force was introduced (schematically showed in Fig. 6), the results at $10 \mathrm{~T}$ of magnetic induction are shown in Fig. 4b, d. The real thermocouples signal (Fig. 4b) demonstrated the changes in a temperature fluctuation. The magnetic force value (Fig. 7a) didn't increase significantly, but what was more important the force on the cold and hot fluids was acting in opposite directions. What is even more important, having a look at Fig. 6, it could be seen that it was acting in contrary to the gravitational force too (Fig. 7a). It suggested slowing down the convection and less intensive heat transfer (visible in Fig. 5), and changes in the flow structure (Fig. 4d). The vortical structure, close to the frequency of 0.01 became dominant in the upper part of enclosure. It could be understand as a separation between the upper and lower parts caused by existence of the magnetic force. The sum of forces (Fig. 7b) exhibits a symmetrical distribution close to the hot and cold walls, where its magnitude slightly decreases with increasing magnetic induction. As the consequence in Fig. 5 decreased value of the Nusselt number in comparison with the natural convection could be observed.

Figures 8, 9, 10, 11, 12, 13, 14, 15, 16 and 17 represent the results for nanofluid $\mathrm{Ag} 0.1$ at various temperature difference values of 5, 15 and $25 \mathrm{~K}$ and various values of magnetic induction. Considering the natural convection of $\mathrm{Ag} 0.1$ at $\Delta T=5 \mathrm{~K}\left(\mathrm{Ra}_{\mathrm{T}}=2.5 \cdot 10^{6}\right)$ the thermocouples signals (Fig. 8) indicated larger temperature fluctuation than presented in Fig. 4 for water. The flow structure represented by the energy spectrum (Fig. 8c) looked similar to the structure showed in Fig. 4c. However, the Nusselt number value (Fig. 9) was slightly lower (about 9.5) due to the changes of fluid properties. The results obtained for $\mathrm{Ag} 0.1$ at $\Delta T=5 \mathrm{~K}$ and magnetic induction of $10 \mathrm{~T}$ are presented in Fig. 8b, d. The real temperature signals (Fig. 8b) were characterised by smaller fluctuations. The magnetic forces (Figs. 10b and 11a) were not symmetrical, but what was more important, the forces acting on the particles close to the cold and hot walls were stronger than the forces acting on the water (the base fluid). Additionally, the magnetic force worked on the particles, close to the cold and hot walls, in the same directions while on water in (a)

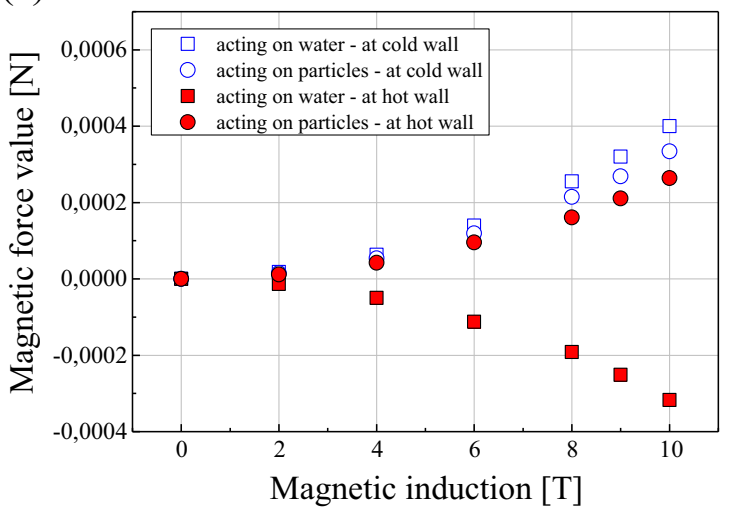

(b)

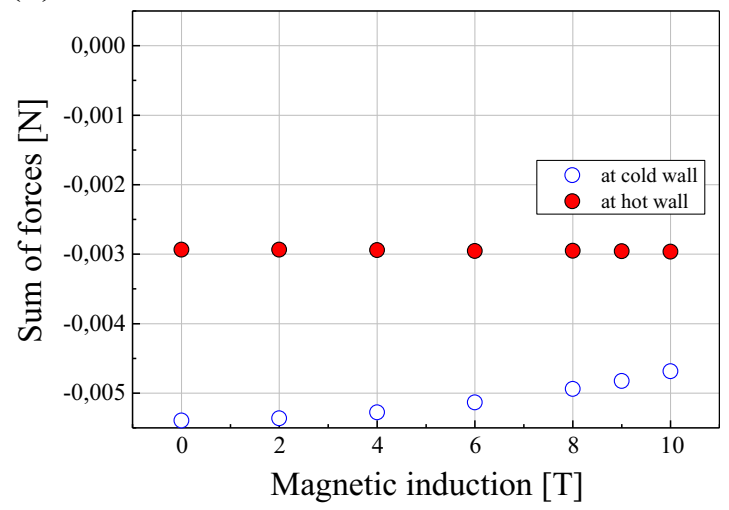

Fig. 17 The magnetic force and the sum of all forces acting in the vicinity of cold and hot walls for $\operatorname{Ag} 0.1$ at $\Delta T=25 \mathrm{~K}\left(\operatorname{Ra}_{\mathrm{T}}=2.2 \cdot 10^{7}\right)$ 
opposite directions. Addition of the magnetic force to the system influenced also the sum of the forces (Fig. 11b), which stopped to be symmetrical. The magnitude was higher close to the cold wall, but it decreased slightly with increasing magnetic induction. Looking at Fig. 8d change of the structure close to the heated wall could be seen. It could suggest that the particles were acting as the mixing agents and intensify the heat transfer. The Nusselt number (Fig. 9) was slightly higher, about 10 , what agreed with the forces calculations and interpretation of the spectral analysis. It should be emphasized that at the same conditions the Nusselt number for water (Fig. 5) decreased to about 9.5.

The natural convection of $\mathrm{Ag} 0.1$ at temperature difference of $\Delta T=15 \mathrm{~K}\left(\mathrm{Ra}_{\mathrm{T}}=10^{7}\right)$ is shown in Figs. 12, 13 and 14. Starting from analysis of the real temperature signals (Fig. 12) it could be said that the frequency of fluctuations increased. Absence of the magnetic field corresponded to absence of the magnetic forces (Fig. 14a). The Nusselt number was higher than in previous cases, but it was obvious, since the temperature difference increased. The flow structure (Fig. 12c) looked very chaotic and the large structures couldn't be identified. The results for the thermo-magnetic convection of $\mathrm{Ag} 0.1$ at $\Delta T=15$ and magnetic induction of $10 \mathrm{~T}$ are presented in Fig. 12b, d. The real temperature signals (Fig. 12b) became irregular. The average temperature didn't change much, but the fluctuations did. The temperature difference increase caused increase in values of the magnetic forces (Fig. 14a), but not their directions. Still the magnetic forces acting on the particles were higher than these acting on the water. The sum of forces changed significantly (Fig. 14b). The difference in magnitude of the forces close to the wall increased. However, influence of the magnetic force on the fluid close to the cold wall is greater than close to the hot wall. The flow structure showed in Fig. 12d suggested appearance of the larger structures (of lower frequency) close to the heated and cooled walls. The Nusselt number (Fig. 13) was very similar to the value obtained for the natural convection. It means that the magnetic force acting on the particles compensated the magnetic force acting on the water. Therefore, the Nusselt number didn't change in comparison with the natural convection. It should be kept in mind that for pure water the Nusselt number decreased with increasing magnetic field strength (see Fig. 5).

The highest studied temperature difference was $25 \mathrm{~K}$. The results for the natural convection of $\operatorname{Ag} 0.1$ at this temperature difference $\left(\mathrm{Ra}_{\mathrm{T}}=2.2 \cdot 10^{7}\right)$ are demonstrated in Figs 15, 16 and 17. The real temperature signals (Fig. 15a) didn't change, but the temperature fluctuations were more time-variable. Figure $15 \mathrm{c}$ suggested that there was no large vortical structure. The system seemed to be uniform (similar signals in the upper and lower parts of the enclosure). The Nusselt number (Fig. 16) was equal to
17.5, suggesting intensive convection. Application of the magnetic field to the system resulted in the changes of real temperature signals Fig. 15b, d. It became less regular than the one showed in Fig. 15a. The values of magnetic forces increased in comparison with Fig. 17a due to the higher temperature difference. However, what was more important, the magnetic force acting on the water close to the cold wall became slightly stronger than forces acting on the particles. The sum of forces magnitude (Fig. 17b) close to the cold wall was much higher than close to the hot wall. Increasing magnetic induction caused its slight decrease. The biggest influence could be found for the flow structure (Fig. 15d), where appearance of large structures could be noticed both in upper and lower parts of the enclosure, however the frequencies slightly differed in both parts. As it could be observed in Fig. 16 the Nusselt number didn't decreased and stayed close to the value obtained for the natural convection.

\section{Summary}

Comprehensive analysis of the magnetic field influence on the diamagnetic nanofluid convection was presented. The heat transfer results were explained with utilization of calculated at starting point forces and spectral analysis representing the flow structure. Such way was necessary since the results were different than obtained for typical diamagnetic fluid, for example the water. First important conclusion is that the nanofluid shouldn't be treated as homogeneous under the influence of magnetic field and that different magnetic properties of the base fluid and the particles should be taken into account. Additional observation for analysed case of particle concentration came from the influence of thermal conditions. At the highest temperature difference the magnetic force acting on water close to the cold wall was slightly higher than acting on the particles. It could lead to the changes in flow structure (appearance of larger structures). This analysis will be extended to the various concentrations of particles and afterward more general conclusions will be presented. The numerical analysis is also in progress. It would definitely improve the understanding of all phenomena occurring in such system.

Acknowledgments This work was supported by the Polish Science Centre (Project No. 12/07/B/ST8/03109).

Open Access This article is distributed under the terms of the Creative Commons Attribution 4.0 International License (http:// creativecommons.org/licenses/by/4.0/), which permits unrestricted use, distribution, and reproduction in any medium, provided you give appropriate credit to the original author(s) and the source, provide a link to the Creative Commons license, and indicate if changes were made. 


\section{References}

1. Maxwell JC (1954) A treatise on electricity and magnetism. Dover Publications, Inc., New York

2. Choi SUS, Eastman JA (1995) Enhancing thermal conductivity of fluids with nanoparticles. In: Proceedings of the 1995 ASME International Mechanical Engineering Congress and Exposition, FED 231/MD, vol. 66, San Franisco, USA, pp. 99-105.

3. Koca HD, Doganay S, Turgut A (2017) Thermal characteristics and performance of Ag-water nanofluid: Application to natural circulation loops. Energy Convers Manag 135:9-20. https://doi.org/10. 1016/j.enconman.2016.12.058

4. Li Y, Xie HQ, Wang JF, Yu W (2011) Study on the Preparation and Properties of Copper Nanoparticles and their Nanofluids. Adv Mater Res 399-401:606-609. https://doi.org/10.4028/www. scientific.net/AMR.399-401.606

5. Gupta M, Singh V, Kumar R, Said Z (2017) A review on thermophysical properties of nanofluids and heat transfer applications. Renew Sust Energ Rev 74:638-670. https://doi.org/10.1016/ j.rser.2017.02.073

6. Cieslinski JT, Fiuk A, Miciak W, Siemienczuk B (2016) Performance of a plate heat exchanger operated with water- $\mathrm{Al}_{2} \mathrm{O}_{3}$ nanofluid. Appl Mech Mater 831:188-197. https://doi.org/10. 4028/www.scientific.net/AMM.831.188

7. Cieslinski JT (2016) Effect of nanofluid concentration on twophase thermosyphon heat exchanger performance. Arch Thermodyn 37:23-40. https://doi.org/10.1515/aoter-2016-0011

8. Bednarz T, Fornalik E, Ozoe H, Szmyd JS, Patterson JC, Lei C (2008) Influence of a horizontal magnetic field on the natural convection of paramagnetic fluid in a cube heated and cooled from two vertical side walls. Int J Therm Sci 47:668-679. https://doi.org/10. 1016/j.ijthermalsci.2007.06.019

9. Wrobel W, Fornalik-Wajs E, Szmyd JS (2010) Experimental and numerical analysis of thermo-magnetic convection in a vertical annular enclosure. Int J Heat Fluid Flow 31:1019-1031. https://oi. org/10.1016/j.ijheatfluidflow.2010.05.012

10. Filar P, Fornalik E, Kaneda M, Tagawa T, Ozoe H, Szmyd JS (2005) Three-dimensional numerical computation for magnetic convection of air inside a cylinder heated and cooled isothermally from a side wall. Int J Heat Mass Transf 48:1858-1867. https://doi. org/10.1016/j.ijheatmasstransfer.2004.10.034

11. Kraszewska A, Pyrda L, Donizak J (2016) Influence of a strong magnetic field on paramagnetic fluid's flow in cubical enclosure. J Phys Conf Ser 760:12011. https://doi.org/10.1088/1742-6596/ 760/1/012011

12. Fornalik-Wajs E, Filar P, Wajs J, Roszko A, Pleskacz L, Ozoe H (2014) Flow structure, heat transfer and scaling analysis in the case of thermo-magnetic convection in a differentially heated cylindrical enclosure. J Phys Conf Ser 530:12041. https://doi.org/10.1088/ 1742-6596/530/1/012041

13. Roszko A, Fornalik-Wajs E, Donizak J, Wajs J, Kraszewska A, Pleskacz L (2014) Magneto-thermal convection of low concentration nanofluids. MATEC Web Conf 18:1-6. https://doi.org/10. 1051/matecconf/20141803006

14. Roszko A, Fornalik-Wajs E (2015) The heat transfer and flow structure analyses of low concentration copper nanofluids in a strong magnetic field. Trans Inst Fluid-Flow Mach 128:29-42

15. Roszko A, Fornalik-Wajs E (2016) Magnetic nanofluid properties as the heat transfer enhancement agent. E3S Web Conf 10:1-8. https://oi.org/10.1051/e3sconf/20161000111

16. Roszko A, Fornalik-Wajs E (2016) Evaluation of diamagnetic nanofluid ability to heat transfer in the strong magnetic field. J Phys Conf Ser 745:32154. https://doi.org/10.1088/1742-6596/ 745/3/032154

17. Hamad MAA, Pop I, Ismail AI (2011) Magnetic field effects on free convection flow of a nanofluid past a vertical semi-infinite flat plate. Nonlinear Anal Real World Appl 12:1338-1346. https://doi. org/10.1016/j.nonrwa.2010.09.014

18. Sheikholeslami M, Ganji DD, Soleimani S (2014) Natural convection heat transfer in a nanofluid filled inclined L-shape enclosure. IJST, Trans Mech Eng 38:217-226. https://doi.org/10.22099/ IJSTM.2014.1967

19. Umadevi P, Nithyadevi N (2016) Magneto-convection of waterbased nanofluids inside an enclosure having uniform heat generation and various thermal boundaries. J Niger Math Soc 35:82-92. https://doi.org/10.1016/j.jnnms.2016.02.001

20. Taurozzi JS, Hackley VA, Wiesner MR (2012) Preparation of nanoparticle dispersions from powdered material using ultrasonic disruption. NIST Spec Publ 1200-2. https://doi.org/10.6028/NIST.SP. $1200-2$

21. Lide David R (ed)(2005) CRC Handbook of Chemistry and Physics, Internet Version 2005. CRC Press, Boca Raton. http:// www.hbcpnetbase.com

22. Tagawa T, Ujihara A, Ozoe H (2003) Numerical computation for Rayleigh-Benard convection of water in a magnetic field. Int J Heat Mass Transf 46:4097-4104. https://doi.org/10.1016/S00179310(03)00223-0

23. Ozoe H, Churchill SW (1973) Hydrodynamic stability and natural convection in newtonian and non-Newtonian fluids heated from below. AIChE Symp Ser Heat Transf 69:126-133. https://doi.org/ 10.1002/aic.690180617

24. Superconducting magnet HF10-100VHT-B technical data, provided by the manufacturer Sumitomo Heavy Industries 